\title{
Thermal and Bonding Properties of Nano Size Carbon Black Filled PDMS
}

\author{
Hao Chen ${ }^{\mathrm{a}, \mathrm{b}}$, Ionel Botef ${ }^{\mathrm{b}}$, Babu Guduri ${ }^{\mathrm{c}}$, V.V. Srinivasu ${ }^{\mathrm{a}}$ \\ ${ }^{a}$ Mechantronics \& Micro Manufacturing, Materials Science and Manufacturing, CSIR, P.O. Box 395, \\ Pretoria 0001, South Africa \\ ${ }^{b}$ School of Mechanical, Industrial and Aeronautical Engineering, University of the Witwatersrand, P.O. WITS, \\ Johannesburg 2050, South Africa \\ ${ }^{c}$ Polymers \& Composites, Materials Science and Manufacturing, CSIR, Port Elizabeth, \\ South Africa
}

\begin{abstract}
We consider Polydimethylsiloxane (PDMS) as a prospective structural material candidate for a Micro Fuel Cell. The introduction of such a polymer as structural material will reduce the mass and the size of the micro fuel cell and therefore optimize the current micro fuel cell models. In this perspective, our work focuses on the tailorability and optimization of thermal, mechanical bonding properties of PDMS with nano size carbon black particles as filler (PDMS-CB). The wt $\%$ of the filler is varied from $10 \%$ to $25 \%$. The mechanical property is characterized by testing the bond strength of the bond between pure PDMS and PDMS-CB composite. The bond between pure PDMS and 10\% carbon black filled PDMS broke at $0.72 \mathrm{MPa}$. The bond has become very strong for other samples with higher wt $\%(>10 \%)$. In this case the bond did not break but the break occurred on the pure PDMS side. The Thermal Gravimetric Analysis (TGA) study has shown good thermal stability of the composite up to $500^{\circ} \mathrm{C}$.
\end{abstract}

Keywords: Micro Fuel cell, Polydimethylsiloxane (PDMS), Nano filled polymer, PDMS-Carbon black composites.

PACS: 81.05.Qk, 82.35.Lr, 82.35.Np

\section{INTRODUCTION}

There is a significant increase in demand for renewable energy sources in the past few decades after the oil crisis in the 1970s. This leads to an intensive research on fuel cells worldwide. With the technology development for the laptop, personal digital assistant (PDA), cell phone and other mobile devices, micro fuel cell as a potential power source has drawn much attention too. Most micro fuel cells are Direct Methanol Fuel Cells fueled by methanol because of their room temperature operation and easy fuel storage.

Typical fuel cell consists of MEA (Membrane Electrode Assembly), flow field plates, electrode plates and end plates. Conductive polymer becomes a suitable structural candidate for fuel cell fabrication due to its electrical conductivity property, light weight, good mechanical and anti-corrosion properties. To utilize polymers as structural candidate for fuel cell fabrication, one has to tailor electrical, thermal and mechanical properties according to the specific needs for a fuel cell design.

Following the successful synthesis of conducting polyacetylene in 1977 by Shirakawa et al. ${ }^{1}$, conducting polymer has drawn great attention due to their potential application in many fields ${ }^{2}$. Most conducting polymers are fabricated by doping with an oxidative/reductive subsistent or by donor/acceptor radicals. But this synthesis process involves chemical reactions and is not easy for mass production. Another way of preparing a conducting polymer is to add conductive filler such as carbon black nano-particles or silver particles into a polymer matrix. This polymer matrix is normally in liquid form at room temperature and can be cured by mixing with a catalyst (cross-linker). Kumar and Sharma ${ }^{3}$ comprehensively 
reviewed the fabrication of different types of conducting polymers, improvement of their conductivities and applications.

\begin{abstract}
APPROACH
We consider Polydimethylsiloxane (PDMS) as a prospective structural material candidate for a micro fuel cell fabrication. PDMS was selected as the polymer matrix in this research because: (i) it is commercially cheap (ii) its easy processability and soft lithography reproducibility (iii) mechanical flexibility. It will reduce the mass and size for fuel cell structure, which is good in the micro fuel cell perspective. Niu et al. ${ }^{4}$ investigated the electrical propertity of polydimethysiloxane (PDMS) composites with infiltration of silver powder (wt83\%-86\%) and carbon black particles (wt10\%-26\%), reported the electrical conductivity of $10^{4} \mathrm{~S} / \mathrm{m}$ with wt $86 \%$ silver and $25 \mathrm{~S} / \mathrm{m}$ with wt $26 \%$ carbon black. While Carbon black as filler shall improve electrical conductivity as reported by Niu et al. ${ }^{4}$, it is important to understand the consequent mechanical bonding and thermal stability properties of these PDMS-CB composites, if they are to be used as structural candidates for fuel cell fabrication. In this paper we report on the synthesis and detailed measurements of bonding and thermal stability properties of these PDMS-CB composites.
\end{abstract}

\title{
EXPERIMENTAL
}

\section{Material}

The conductive fillers used are nano sized carbon black (20-40nm, Carbon black, Vulcan XC72, Cabot Inc.). The polymer matrix is PDMS (Sylgard 184 Silicone Elastomer, Dow Corning).

\section{Sample Preparation}

Nano size $(\sim 40 \mathrm{~nm})$ carbon black filled PDMS composite samples were prepared with specific wt\% (10-25\%) of Carbon black. We chose this range because, it is well established that these composites have good electrical conductivities in this particular range ${ }^{4}$.

The beaded carbon black was first dispersed in methanol then ultrasonicated for $30 \mathrm{~min}$ and then mixed with the PDMS, the blend was mechanically mixed for 24 hours to obtain homogenous dispersion, then the curing agent was add. After the ultrasonic and vigorous mixing, the solvent methanol was evaporated, so the weight of the methanol was not included when calculating the composition. The blends were degassed under vacuum. The mixture was oven baked to cure for 8 hours at $60^{\circ} \mathrm{C}$. It is to be noted that the Carbon black particles were easy to mix with PDMS gel owing to their good wetting properties and in general leads to a uniform distribution in PDMS ${ }^{4}$.

\section{Characterization}

Scanning Electron Microscopy was used for morphological study.

The tensile bond test was carried out using a Tinius Olsen tensile machine at room temperature according to the ASTM D 3039/D 3039M standard. Samples were prepared for this test in the following way. The PDMS-CB composite was casted and cured in a mold first 
$(30 \mathrm{~mm} * 10 \mathrm{~mm} * 5 \mathrm{~mm})$, then the pure PDMS was covered on top of the cured PDMS-CB composite to obtain the bonded sample $(60 \mathrm{~mm} * 10 \mathrm{~mm} * 5 \mathrm{~mm})$ as shown in figure 1 .

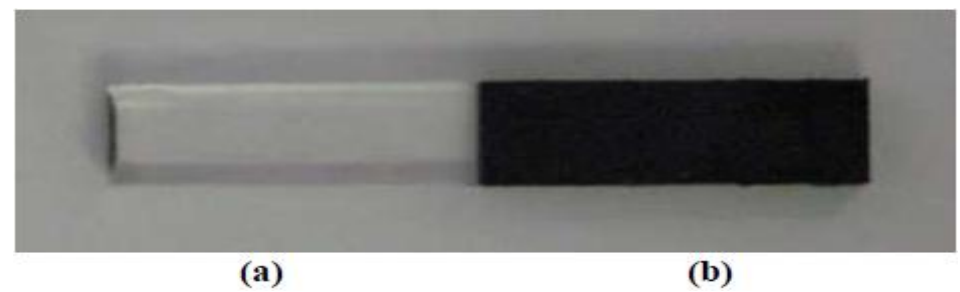

FIGURE 1. Tensile bond test sample (a) pure PDMS and (b) PDMS-CB composite

Thermal Gravimetric Analysis (TGA) for thermal stability/degradation was performed on a TA Instrument TGA Q500 in nitrogen atmosphere. The heating rate was $10^{\circ} \mathrm{C} / \mathrm{min}$. The measurement range was from room temperature to $800^{\circ} \mathrm{C}$.

\section{RESULTS AND DISSCUSION}

\section{Bonding Tensile Test}

Bonding property was investigated and results were tabulated in table 1, the pure PDMS and $10 \%$ PDMS-CB composite bonded sample broke at the bonding part with $0.72 \mathrm{MPa}$ stress. The rest of the samples have shown an increasing bond strength as the filler fraction was increased $(>10 \%)$. The bond did not break but breaks occurred on the PDMS side. In this experiment, the exact bond strength were not obtained due to the PDMS breakage, however, this indicates that the PDMS and PDMS-CB composites were well bonded, and this could prevent fuel leakage in a micro fuel cell application. This is one of the positive aspects of PDMS-CB composites in the fuel cell fabrication perspective.

TABLE 1. PDMS to PDMS-CB composites Bonding test results

\begin{tabular}{ccc}
\hline CB\% & Stress at break (MPa) & Broken Part \\
\hline CB10\% & $0.72 \pm 0.09$ & At Bond \\
CB13\% & $0.98 \pm 0.04$ & PDMS End \\
CB16\% & $0.91 \pm 0.16$ & PDMS End \\
CB19\% & $0.91 \pm 0.11$ & PDMS End \\
CB22\% & $1.12 \pm 0.13$ & PDMS End \\
CB25\% & $1.27 \pm 0.19$ & PDMS End \\
\hline
\end{tabular}

\section{Thermal Gravimetric Analysis}

The thermal stability behaviors of the PDMS and PDMS-CB composites with different filler load are shown in figure 2. The analysis indicates that the PDMS is thermally stable up to $250{ }^{\circ} \mathrm{C}$ with a weight loss of $1 \%$. Sharp losses of weight occurred at $552{ }^{\circ} \mathrm{C}(83 \%$ remaining), $709^{\circ} \mathrm{C}\left(53 \%\right.$ remaining) and at $800{ }^{\circ} \mathrm{C}, 35 \%$ of the weight was left. 
TGA of PDMS-CB composites shown that the infiltration of carbon black into the polymer matrix have enhanced the stability of PDMS, (see inset of figure 2) in the temperature range of $510{ }^{\circ} \mathrm{C}$ to $550{ }^{\circ} \mathrm{C}$, the sample degrades faster as the filler concentration increases, at $510^{\circ} \mathrm{C}$, PDMS-CB composites samples have weight loss of $10 \%-15 \%$ for all concentrations, however, at $550{ }^{\circ} \mathrm{C}, 10 \% \mathrm{CB}$ loading sample has $76 \%$ weight remaining while $25 \% \mathrm{CB}$ sample has only $55 \%$ weight left. Also at $800{ }^{\circ} \mathrm{C}$ more than $40 \%$ was remaining for PDMS-CB as compared to 35\% weight for pure PDMS. The thermal stability/degradation performance of our PDMS-CB composites is compared to PDMS/CF/PPy and PDMS-Pth composites in the literature ${ }^{5.6}$. For example, in PDMS-CB composites the weight loss is only $10-15 \%$ at $\sim 500{ }^{\circ} \mathrm{C}$, which is better as compared to $18 \%$ weight loss at $399{ }^{\circ} \mathrm{C}$ in PDMS-CF/PPy compsites ${ }^{5}$. Also in the case of PDMS-Pth composite, Mehmet Sankir et $\mathrm{al}^{6}$ reported a derivative peak due to solvent loss at $75^{\circ} \mathrm{C}$. We do not have any such solvent loss low temperature peak for our samples (see Fig 3). Further in PDMS-Pth composite the onset of degradation starts at $<130{ }^{\circ} \mathrm{C}$ and already $10 \%$ weight loss occurred around $250{ }^{\circ} \mathrm{C}$. In view of these report in the literature, our PDMS-CB composites have better thermal degradation properties.

The composites are very stable at lower temperature range $\left(30{ }^{\circ} \mathrm{C}\right.$ to $\left.200{ }^{\circ} \mathrm{C}\right)$, which is typically the operation environment for fuel cells.

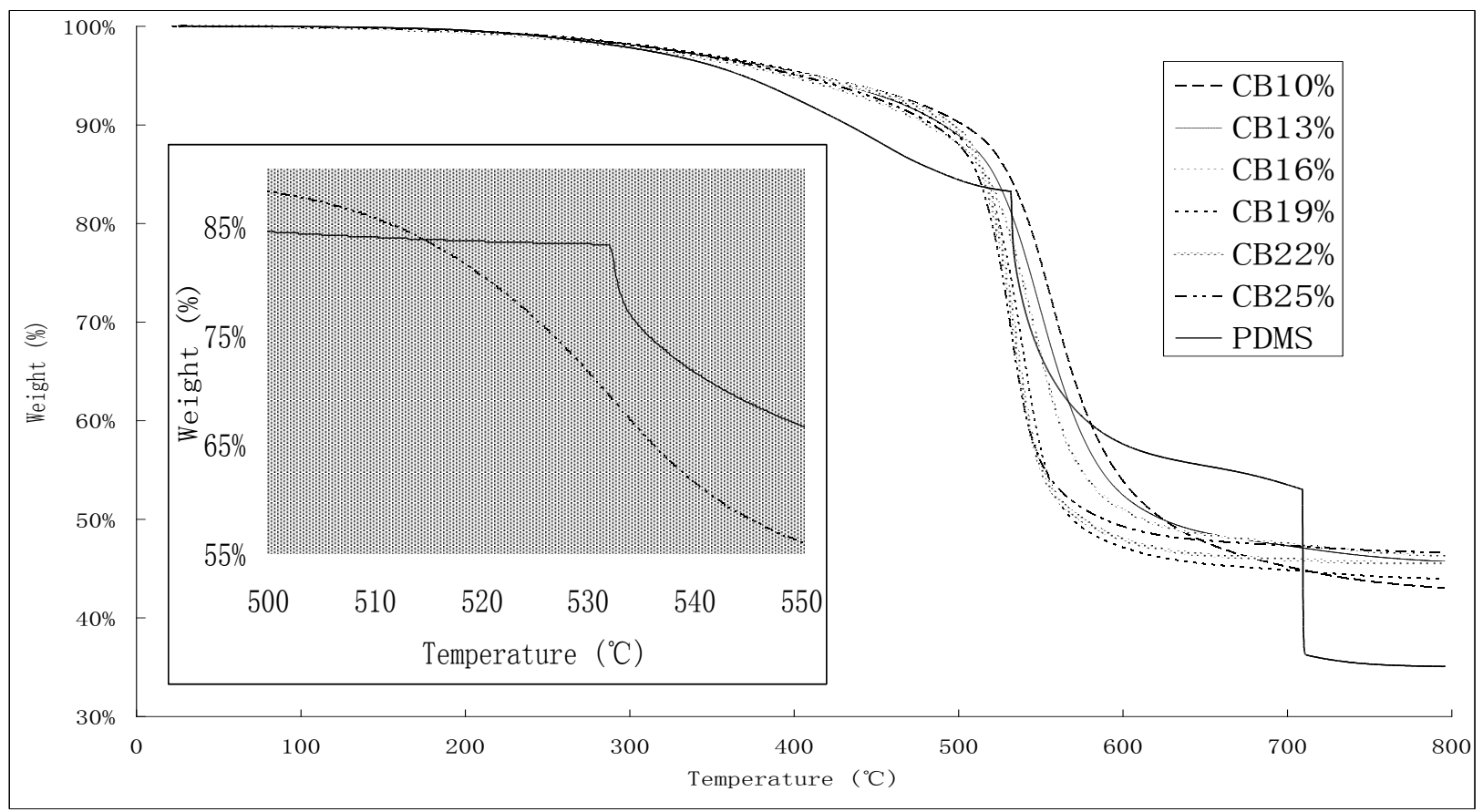

FIGURE 2. TGA analysis of pure PDMS and PDMS-CB composites. Inset is a zoom between 500 and $550{ }^{\circ} \mathrm{C}$

\section{Scanning Electron Microscopy}

SEM photograph (Fig 4) was taken for the 10\% CB sample. It was observed that the particle dispersion was reasonably homogenous. The size and shape of the particle appeared irregular between 50nm and150nm due to the particle agglomeration. The micron size round shape object in the middle is an air bubble. Air bubbles may affect both bonding property and porosity. Porosity is a crucial issue in fuel cells, this might leads to fuel permeation and also affects the mechanical stability of the structure. 


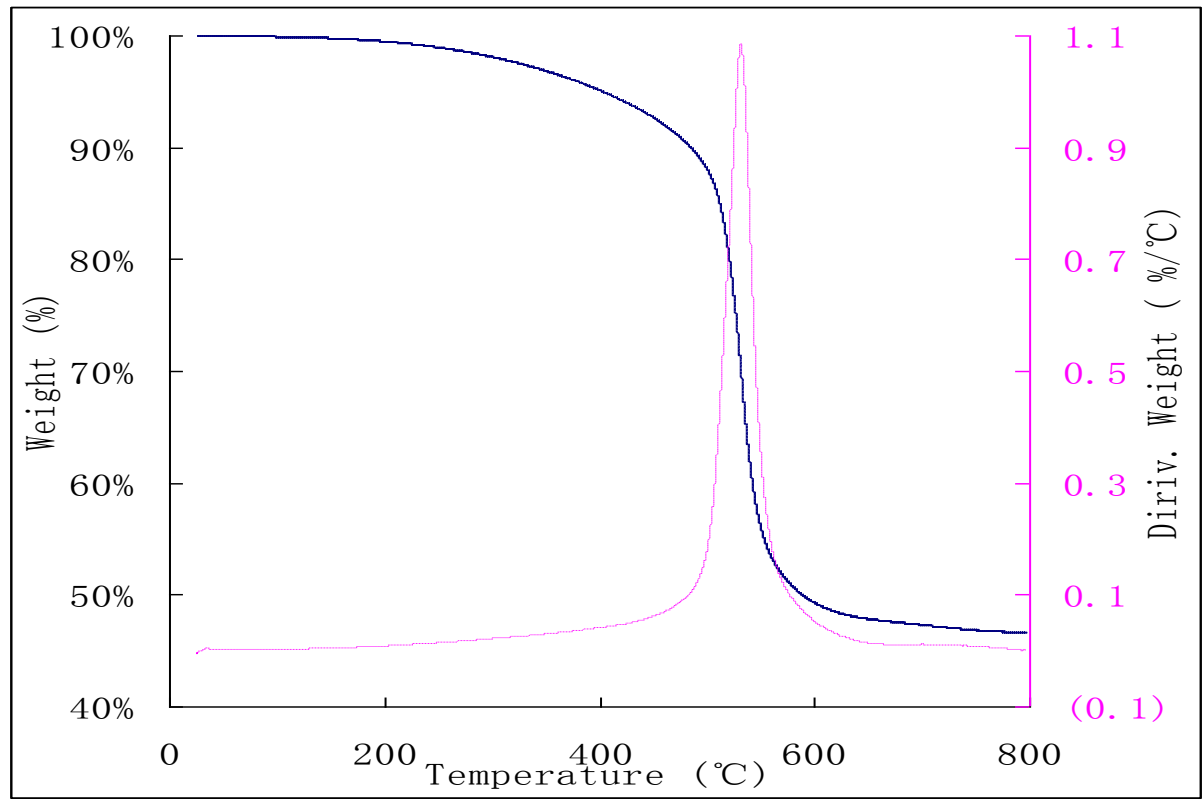

FIGURE 3. Typical TGA and its derivative plot for our PDMS-CB

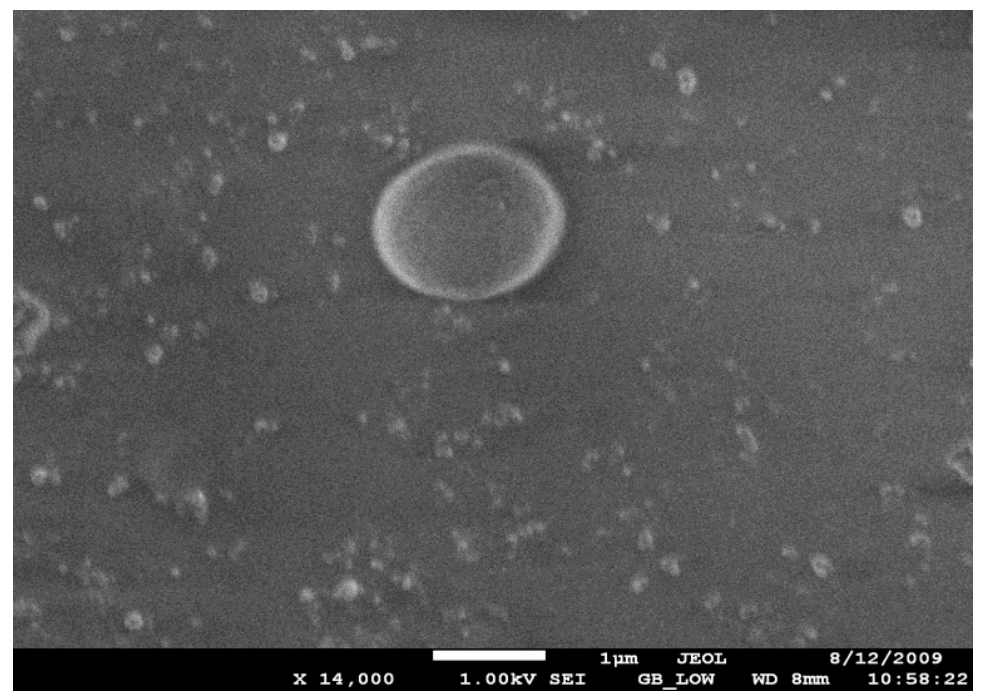

FIGURE 4. SEM of $10 \%$ PDMS-CB

\section{CONCLUSION}

PDMS-CB composites with filler wt $\%$ in the specific range of $10-25 \%$ (in this range these composites show good electrical conductivities) were prepared. Thermal stability/degradation and mechanical bonding properties of these composites were studied in detail. These properties, together with the electrical properties are important for these composites to be utilized as structural materials for fuel cell fabrication. We found that these composites have promising thermal stability and mechanical bonding properties in the micro fuel cell fabrication perspective. However, several issues such as improvement of the mixing method to remove bubbles and particles agglomeration need to be addressed before the composites can be utilized in the micro fuel cell applications. 


\section{ACKNOWLEGEMENT}

The authors wish to acknowledge Kevin Land for a CSIR-SRP proposal initiative and Council for Scientific and Industrial Research (CSIR) for the financial support. The National Center for Nano Structured Materials is acknowledged for equipmental support.

\section{REFERENCE}

1. H. Shirakawa, E.J. Louis, A.G. MacDiarmid, C.K. Chiang, A.J. Heeger. J. Chem. Soc, Chemical Commun. 16, 578-580 (1977).

2. Anand J, Palaniappan S, Sathyanarayana DN. Progress in Polymer Science 23, 993-1018 (1998).

3. Kumar D, Sharma RC. European Polymer Journal 34, 1053-60 (1998).

4. Niu X, Peng S, Liu L, Wen W, Sheng P.. Adv Mater 19, 2682-6 (2007).

5. Çakmak G, Küçükyavuz Z, Küçükyavuz S, Çakmak H. Composites Part A; 35, 417-21 (2004).

6. Sankır M, Küçükyavuz Z, Kuecuekyavuz S. J Appl Polym Sci 87, 2113-9 (2003). 